Goldschmidt 2021 Abstract

https://doi.org/10.7185/gold2021.3561

\section{Experimental investigation of sulfidation of silicates, glasses and melts under reducing conditions}

\author{
CHRISTIAN J. RENGGLI ${ }^{1}$, ANDREAS MORLOK ${ }^{2}$, \\ STEPHAN KLEMME $^{3}$, JASPER BERNDT ${ }^{4}$, IRIS WEBER ${ }^{2}$ \\ AND HARALD HIESINGER ${ }^{2}$ \\ ${ }^{1}$ Institut für Mineralogie, Universität Münster \\ ${ }^{2}$ Institut für Planetologie, Universität Münster \\ ${ }^{3}$ Universität Münster \\ ${ }^{4}$ University of Münster \\ Presenting Author: renggli@uni-muenster.de
}

Sulfur is a key volatile element to understand processes from accretion in the solar nebula, to core formation, and planetary volcanism. In most of these environments polyvalent $S$ occurs in its reduced state. S-rich gases are predicted, for example, driving lunar pyroclastic eruptions [1]. Reactions of these gases with silicates only leave indirect evidence, such as in sulfidation textures observed in lunar rocks [2] or enstatite chondrites [3]. To better constrain these processes, we present experimental results on sulfidation reactions between reduced S-C-O gas and silicates.

We ran the experiments in evacuated silica glass tubes with the minerals olivine $\left(\mathrm{Fo}_{92}\right)$, anorthite, diopside, and three glasses with Mercury compositions; high-Mg, low-Mg and high-Al [4]. The silicates are placed in a graphite cup in the glass tube, above a graphite cup that contains elemental sulfur (Fig. 1). At high temperatures $\left(800-1200{ }^{\circ} \mathrm{C}\right)$ the sulfur forms a gas and reacts with the silicate samples. The graphite cups control the $\mathrm{fO}_{2}$ at the C-CO buffer [5]. The experiments were run for $24 \mathrm{~h}$.

At $800{ }^{\circ} \mathrm{C}$ sulfidation is kinetically limited and only occurs on the surface of mineral and glass grains. However, at higher temperatures $\left(1000,1200{ }^{\circ} \mathrm{C}\right)$ the reaction becomes increasingly pervasive and creates porosity in glasses and minerals (Fig.2). Observed sulfide reaction products include $\mathrm{CaS},(\mathrm{Ca}, \mathrm{Mg}) \mathrm{S}$, $(\mathrm{Ti}, \mathrm{Fe}, \mathrm{Ca}, \mathrm{Mg}) \mathrm{S}$ and $(\mathrm{Fe}, \mathrm{Ti})_{1-\mathrm{x}} \mathrm{S}$. The $\mathrm{Mg} / \mathrm{Ca}$-ratio in the sulfides is a function of the silicate composition and increases with temperature. An additional important reaction product is $\mathrm{SiO}_{2}$.

Our experiments show that sulfidation reactions of silicates are an efficient sink for sulfur at reducing conditions. These gassolid reactions may have played a key role in the enrichment of S at the surface of Mercury. Therefore, the experimental products are used as analog materials and analyzed by mid-infrared spectrometery as a reference for space missions (e.g. MERTIS onboard the ESA/JAXA mission BepiColombo to Mercury [6]).

[1] Renggli et al. (2017) GCA, 10.1016/j.gca.2017.03.012. [2] Shearer et al. (2012) GCA, 10.1016/j.gca.2011.11.031. [3] Fleet \& MacRae GCA, 10.1016/0016-7037(87)90333-4. [4] Morlok et al. (2021) Icarus, j.icarus.2021.114363. [5] Renggli \& Klemme (2021) JGR Planets, 2020JE006609. [6] Hiesinger et al. (2020) Space. Sci. Rev., 10.1007/s11214-020-00732-4.

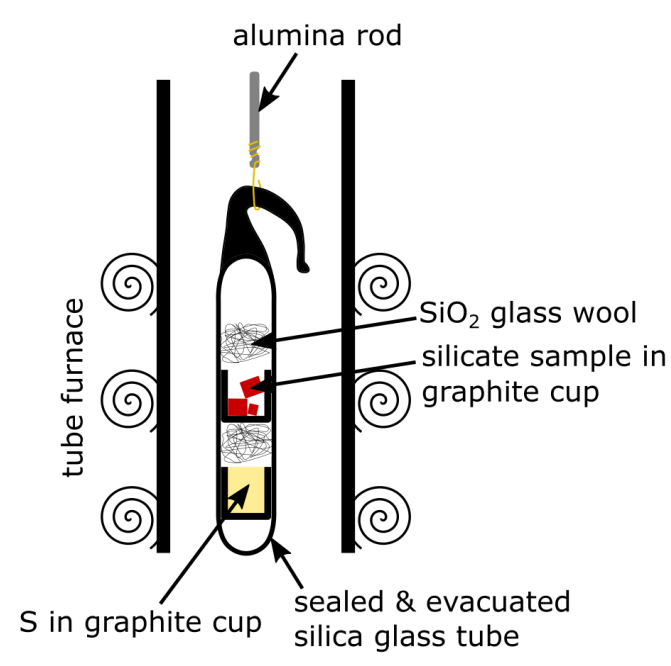

Fig. 1: Experimental set-up. Evacuated silica glass tube suspended in the hot zone of a vertical tube furnace. The graphite cups control the $\mathrm{fO}_{2}$ at the C-CO buffer and the elemental S forms a S-C-O gas phase at 800, 1000 and $1200^{\circ} \mathrm{C}$.
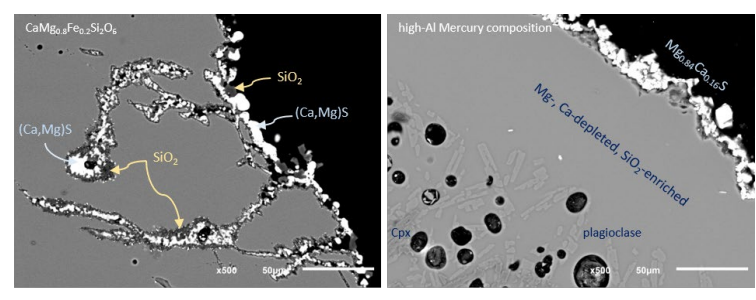

Fig. 2: Back-scattered electron images of cross-sections through diopside (left) and a high-Al Mercury melt [4] (right)

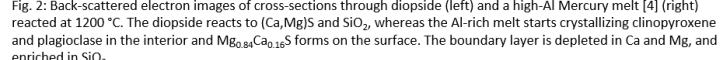

